\title{
Chapter 8 \\ Public Service Provision in China: Towards a More Equal Access System
}

\author{
Jingjing Shan, Yanan Geng, Jin Fu, and Binglei Yu
}

\begin{abstract}
The challenge facing urban policymakers is how to tackle the longstanding differences in social welfare and basic public services provision for migrant and incumbent workers arising from the dual-household registration system. In this chapter, we quantify inequalities in access to basic public services between migrant workers and the local urban population across different regions of China. We consider both inequalities within urban areas, and inequalities that exist between urban and rural areas. For urban areas, we find large inequalities in access to basic public services between the indigenous urban population and migrant workers. There are also significant differences between urban and rural areas. The level of basic public services in the West of China lags behind other regions. Across China as a whole, the gap within regions is greater than the gap between regions. Internal variations within a region arise mainly from inequality in access to basic public services between urban and rural populations and across urban neighbourhoods. Chinese public services are characterised by 'dualisation' in urban-rural provision and 'fragmentation' across regions in terms of the level and quality of service. These two features constitute a formidable obstacle for the 'citizenisation' of migrant workers. We provide detailed examples from across China of countermeasures and strategies currently being implemented to reduce inequalities in public service provision.
\end{abstract}

Keywords Migrant workers $\cdot$ Citizenisation $\cdot$ Basic public service $\cdot$ Inequality

\footnotetext{
J. Shan $(\varangle)$

Research Institute for Eco-civilization, Chinese Academy of Social Sciences, Beijing, China e-mail: shanjj2008@126.com

Y. Geng $\cdot$ J. Fu

Graduate School of Chinese Academy of Social Sciences, Beijing, China

e-mail: 28069127@qq.com

J. Fu

e-mail: fujin0712@foxmail.com

B. Yu

School of Economics and Commerce, South China University of Technology, Guangzhou, Guangdong, China

e-mail: icy2001@126.com
}

(C) The Author(s) 2021

G. Pryce et al. (eds.), Urban Inequality and Segregation in Europe and China,

The Urban Book Series, https://doi.org/10.1007/978-3-030-74544-8_9 


\subsection{Introduction}

In this chapter, we investigate the inequalities in access to public services that have emerged as a result of the urbanisation process over the past 40 years. The urbanisation rate in China increased from $17.9 \%$ in 1978 to $59.58 \%$ in 2018, with an annual average growth rate of $1.04 \%$. The urban population increased from 172 to 831 million, with an annual average increase of 16 million. Since 1995, the rate of urbanisation has accelerated, increasing by $1.33 \%$ every year. The urban population has also increased by more than 20 million every year, which is greater than the total population of a medium-sized European country. (For a more detailed discussion of the phases of China's migration, urbanisation and growth, see Chap. 5).

China's urbanisation process, however, can be considered incomplete in the sense that although large numbers of migrant workers have settled in cities and are counted among the urban population, they do not have urban hukou (or non-agricultural hukou), which confers citizenship rights. Despite moving to the city, the status of their hukou registration remains rural or agricultural, which means they do not have full rights of citizenship in terms of access to urban public services. ${ }^{1}$ They have become industrial workers and made a great contribution to urban construction and development. Nevertheless, they are restricted by the long-standing urban/rural division due to the prevailing dual system of household registration, and cannot enjoy the same access to basic public services as the permanent urban population. They have restricted access to employment, medical treatment, provision for the aged, children's education, welfare housing and social security. As a consequence, it is very difficult for them to integrate into urban society fully. They become the 'migrant bird' population, wandering between urban and rural areas. Large-scale and pendulumtype population movements encourage families to draw on facilities and resources in their native rural homelands and cities. It also brings about household separation, left-behind children, a predominance of elderly and women in rural areas and many other social problems. These may generate many risks and hidden dangers to the healthy and stable development of the economy and society.

Both the National New Urbanization Plan (2014-2020) unveiled in 2014, and the Report of the 19th National Congress of the Communist Party of China in 2017, placed a priority on new 'people-centred' urbanisation processes and improved quality. New models of urbanisation must encompass an increase in the number of towns, the expansion of urban space and the higher proportion of the population living in cities. They must also deal with the transformation of human production and living standards through improvements in the quality of urban development.

The key feature of these new models of urbanisation is that they are 'peoplecentred'. They aim to promote the 'citizenisation' of migrant workers through the process of industrialisation and urbanisation in order to comprehensively transform the employment prospects, identity, status, ideology, working conditions and living standards of migrant workers. The aim is to transform them into urban residents and

\footnotetext{
${ }^{1}$ Migrant workers are those who are registered for census returns in rural areas, but who work outside their registered location for six months and more each year.
} 
enable them to obtain the same basic public services and social benefits that registered urban residents currently enjoy, thereby improving living standards and community cohesion. Whether this process is considered in a more specific sense- the status and living conditions of migrant workers - or in broader societal terms, the promotion of the equality of access to basic public services is a key factor and a core challenge. The so-called 'equalisation' of basic public services means that the government should provide common and roughly equal public services across society. These services should be appropriate for various economic and social development levels and should reflect principles of fairness and justice. They should allow all members of society to share equally in the achievements of China's reform and opening-up policies and in the country's economic and social development.

The Chinese government has set development goals of permanently settling around 100 million migrant workers in cities and extending access to the benefits of urbanisation to another 100 million people in central and western areas. In order to achieve this, there needs to be equal access to basic public services, making it easier for migrant workers to integrate successfully into urban society. The goal is also to achieve more equal access to public services between urban and rural areas and across different regions. There is an ultimate commitment to encourage 'about 100 million people' to remain within the central and western regions allowing them to benefit from 'nearby urbanisation' in their own areas.

Many studies show that the main challenge to this core mission is the slow progress of reform of the urban-rural dual-household registration system. This leads to disparities in access to social welfare and basic public services and related social problems (Zhao and Wang 2002; Liu et al. 2008; Cai et al. 2005; Zhao 2006; Zhang 2008; Ji 2009).

Our focus in this article is on the following research questions:

- To what extent do gaps exist in the basic public services of China?

- Are such gaps mainly between different regions, urban and rural areas, or between migrant workers and local residents in cities?

- What are the key challenges for China to overcome in order to promote equality of access to basic public services for migrant workers?

Our hope is that research and discussion on these problems can strengthen the determination of regional governments to accelerate the process of equalising access to basic public services and the 'citizenisation' of migrant workers.

A considerable body of research has emerged from Chinese scholars on reducing inequality in access to basic public services. For example, Hu et al. (2013) utilised data from 2006 to 2010 to comprehensively evaluate the levels of development in basic public services during the '11th Five-Year Plan' period. They found very evident increases in the levels of access to public services across various regions. In the meantime, due to rapid progress in less developed areas, regional gaps were decreasing, with levels of access gradually becoming more equal. The assimilation rates within infrastructure and basic environmental services increased the fastest. Yu (2012) utilised the Theil index to measure the gaps in public investment in compulsory education in different regions of China from 1995 to 2009. The study concluded that 
these gaps decreased by varying degrees from 2005 to 2009. Huang and Fang (2008) analysed the internal and regional differences across eastern, central and western regions in aspects of public health expenditure from 1997 to 2005 . They found that the overall gaps represented a downward trend from 2000, which mainly came from the internal differences within each region. Research conducted by Ouyang and Ding (2011) found that from 2000 to 2008, the difference in social security expenditure presented a downward and fluctuating trend. The differences mainly derived from inside the regions, with relatively large variations within the eastern region and relatively smaller variations across central and western regions. Wang (2012) applied an empirical analysis to the configurations of basic public cultural service resources (such as cinemas, library books, and libraries) in eastern, central and western regions of China in 1999 and 2009, and found a consistent upward trend in equality of access in recent years. At the same time there were increasing disparities between different provinces, regions and municipalities. Lu (2012) studied data from 31 provinces from 2003 to 2009 and found that the overall levels of basic public services increased markedly. Various regions presented obvious step characteristics. The overall level of basic public services in the eastern region was higher than in central regions, which were higher than in the western region. But it should be noted that from 2008, the basic public service level of the western region exceeded the central region. Zhao (2013) utilised the statistical data from 2011 and conducted a comparative evaluation on the rural grass-roots medical service levels of 28 provinces across mainland China. The analysis indicated that in general the overall degree of differentiation in levels of rural grass-roots medical services positively correlated with the total fiscal revenue of each province, region or municipality. Feng (2014) adopted an entropy method and conducted spatial analysis into the development and quality of basic public services across prefecture-level cities in 2001 and 2010. This showed that the public services within most regions in 2001 were seriously insufficient, and the overall public service level increased at a lower rate in 2010. Ren (2009) applied Gini coefficient to analyse inter-provincial basic public service levels from 2000 to 2006. The study identified an increasing trend for disparities in public services provision across different provinces in China.

While Chinese scholarship on reducing inequality of access to public services has created a useful theoretical framework, the research perspectives mainly focus on regional comparison or on certain individual public services. There are few systematic studies around the 'citizenisation' of migrant workers, and a particular shortage of studies examining disparities across different groups within a region-such as between urban dwellers and migrant workers. At the same time, there is insufficient research into the social costs for increasing equality in access to basic public services. 


\subsection{Evaluating Levels of Equality in Accessing Basic Public Services}

At present, China is vigorously promoting a new people-centred approach to urbanisation, and focuses on solving three so-called ' 100 million people' problems. ${ }^{2}$ If China is to guide about 100 million people into a localised urbanisation process in central and western regions, we need to further reduce inequality in access to basic public services across different regions and between urban and rural areas.

Our approach involves three steps: firstly, to establish the basic public service evaluation index system based on a list of measures that capture the availability of public services, such as the number of doctors per 10,000 people, and the percentage of people with unemployment insurance. Secondly, to use the TOPSIS (Technique for Order of Preference by Similarity to Ideal Solution) method to measure and evaluate the development levels of basic public services. Finally, to use the Theil index model to measure and evaluate inequality of access to basic public services between migrant workers and local urban populations in eastern, central and western regions, between urban and rural areas and within cities throughout the country respectively.

\subsubsection{The Evaluation Index System}

In response to the need to evaluate the degree of equality in access to basic public services, we have selected 15 evaluation factors to establish a representative and scientific evaluation index system for public services based on available data. Such factors mainly focus on medical health, compulsory education, cultural facilities and social security (see Table 8.1).

\subsubsection{Establish Theil Index Model to Measure Equality of Access to Basic Public Services}

There are many measurement methods which could reflect the degree of inequality in access to public services, such as the coefficient of variation, Gini coefficient and range ratio. Although these indices could properly reflect the overall level of equality, it is difficult to use them to reflect the contributions that particular aspects of inequality—such as inequality within regions versus inequality between themmake to the overall levels. The Theil index model is our preferred approach as it

\footnotetext{
${ }^{2}$ Three ' 100 million people' problems is the name given to development goals put forward in the Chinese government work report 2014, i.e. 'promote about 100 million migrant workers settling down in cities and towns, transform the shanty towns and villages in cities where about 100 million people live, and guide another 100 million people into the urbanisation process in central and western regions.'.
} 
Table 8.1 Evaluation index system of basic public services

\begin{tabular}{|c|c|}
\hline Primary index & Secondary index \\
\hline \multirow[t]{3}{*}{ Medical health } & $\begin{array}{l}\text { Number of hospitals and health centres for every ten thousand } \\
\text { persons (hospitals } / 10,000 \text { persons) }\end{array}$ \\
\hline & $\begin{array}{l}\text { Number of doctors every ten thousand persons (doctors } / 10,000 \\
\text { persons) }\end{array}$ \\
\hline & $\begin{array}{l}\text { Number of beds in hospitals and health centres for every ten thousand } \\
\text { persons (beds } / 10,000 \text { persons) }\end{array}$ \\
\hline \multirow[t]{6}{*}{ Compulsory education } & $\begin{array}{l}\text { Number of middle schools for every ten thousand persons } \\
\text { (schools } / 10,000 \text { persons) }\end{array}$ \\
\hline & $\begin{array}{l}\text { Number of primary schools for every ten thousand persons } \\
\text { (schools } / 10,000 \text { persons) }\end{array}$ \\
\hline & $\begin{array}{l}\text { Number of middle school students for every ten thousand persons } \\
\text { (persons } / 10,000 \text { persons) }\end{array}$ \\
\hline & $\begin{array}{l}\text { Number of primary school students for every ten thousand persons } \\
\text { (persons/10,000 persons) }\end{array}$ \\
\hline & $\begin{array}{l}\text { Number of middle school full-time teachers for every ten thousand } \\
\text { persons (persons } / 10,000 \text { persons) }\end{array}$ \\
\hline & $\begin{array}{l}\text { Number of primary school full-time teachers for every ten thousand } \\
\text { persons (persons } / 10,000 \text { persons) }\end{array}$ \\
\hline \multirow[t]{3}{*}{ Cultural facilities } & $\begin{array}{l}\text { Number of cinemas for every ten thousand persons (cinemas/10,000 } \\
\text { persons) }\end{array}$ \\
\hline & $\begin{array}{l}\text { Number of public library books for every ten thousand persons } \\
\text { (books } / 10,000 \text { persons) }\end{array}$ \\
\hline & $\begin{array}{l}\text { Number of public libraries for every ten thousand persons } \\
\text { (libraries/10,000 persons) }\end{array}$ \\
\hline \multirow[t]{3}{*}{ Social security } & Coverage of urban employees' basic endowment insurance (\%) \\
\hline & Coverage of urban basic medical insurance $(\%)$ \\
\hline & Coverage of unemployment insurance (\%) \\
\hline
\end{tabular}

makes up this deficiency due to its 'decomposability' - that is the Theil index can be 'decomposed' to show the contributions to overall inequality made by particular subgroups and areas as a way of investigating the structure of inequality. We use this decomposition approach below to measure the degree of inequality across basic public services among different regions, between urban and rural areas and between different populations throughout the country.

Theil index is initially used for measuring the income gap or the degree of inequality between individuals or regions. A larger Theil index indicates a larger overall income difference between individuals or regions; a smaller Theil index indicates a smaller overall income difference between individuals or regions; a Theil index of 0 means the income is completely equal. The fundamental formula of the Theil index is: 


$$
T=\frac{1}{n} \sum_{i=1}^{n} \frac{y_{i}}{\bar{y}} \lg \left(\frac{y_{i}}{\bar{y}}\right)
$$

Of which, $T$ indicates Theil index, $y_{i}$ indicates the income level of individual $i$, and $\bar{y}$ indicates the average income of all individuals. When formula (8.1) is applied to measure the inequality in access to basic public services, income is replaced by population as the weight, and the above formula can be converted into:

$$
T_{\text {total }}=\sum_{i=1}^{n} \frac{p_{i}}{p} \lg \left(\frac{\mathrm{P}_{i} / \mathrm{R}_{\mathrm{i}}}{\mathrm{P} / \mathrm{R}}\right)
$$

Of which, $p_{i}$ indicates the basic public service level of city $i, p$ indicates the basic public service level of the whole country, $R_{i}$ indicates the population of city $i$, and $R$ indicates the total population of the whole country. The degree of inequality across basic public services is inversely proportional to $T$. The smaller $T$ is, the lower the level of inequality.

We use the bivariate Theil index to investigate the level of equal access to basic public services across the whole country. Firstly, we divide the Theil index into inter-regional gaps and intra-regional gaps, and formula (8.2) will be converted into:

$$
\begin{gathered}
T_{\text {total }}=T_{\text {inter-regional }}+T_{\text {intra-regional }} \\
T_{\text {inter-regional }}=\sum_{j=1}^{4} \frac{p_{j}}{\mathrm{p}} \lg \left(\frac{p_{j} / R_{j}}{\mathrm{p} / R}\right) \\
T_{\text {inter-regional }}=\sum_{j=1}^{4} \frac{p_{j}}{p} T_{j} .
\end{gathered}
$$

where $j$ denotes region. The Theil index of each region is then further split into the gap between urban and rural areas and the gap within urban or rural areas. The Theil index $T_{\mathrm{j}}$ within region $j$ can be indicated as:

$$
\begin{gathered}
\boldsymbol{T}_{\mathbf{j}}=\boldsymbol{T}_{\mathbf{j} \text { urban-rural }}+\boldsymbol{T}_{\mathbf{j} \text { intra-urban or rural }} \\
\mathrm{T}_{\mathrm{j} \text { urban-rural }}=\frac{\mathrm{P}_{\mathrm{ju}}}{\mathrm{P}_{\mathrm{j}}} \lg \left(\frac{\mathrm{P}_{\mathrm{ju}} / \mathrm{R}_{\mathrm{ju}}}{\mathrm{P}_{\mathrm{j}} / \mathrm{R}_{\mathrm{j}}}\right)+\frac{\mathrm{P}_{\mathrm{jr}}}{\mathrm{P}_{\mathrm{j}}} \lg \left(\frac{\mathrm{P}_{\mathrm{jr}} / \mathrm{R}_{\mathrm{jr}}}{\mathrm{P}_{\mathrm{j}} / \mathrm{R}_{\mathrm{j}}}\right)
\end{gathered}
$$

where $\mathrm{T}_{\text {jurban-rural }}$ is the Theil index, which reflects the basic public service gap between urban and rural areas of region $j, \mathrm{P}_{\mathrm{ju}}$ indicates the basic public service level in the urban area of region $j, \mathrm{P}_{\mathrm{jr}}$ indicates the basic public service level in the rural area of region $j, \mathrm{P}_{\mathrm{j}}$ indicates the basic public service level of region $j, \mathrm{R}_{\mathrm{ju}}$ indicates 
the urban population of region $j, \mathrm{R}_{\mathrm{jr}}$ indicates the rural population of region $j, \mathrm{R}_{\mathrm{j}}$ indicates the total population of region $j$.

The Theil index, which reflects the inequality of access to basic public services within the urban and rural areas in each region, is further divided into the Theil index $\mathrm{T}_{\mathrm{ju}}$ which reflects the level of equal access to basic public services within urban areas across the region, and Theil index $\mathrm{T}_{\mathrm{jr}}$ which reflects the inequality of access to basic public services of rural area in the region, then:

$$
\begin{gathered}
\boldsymbol{T}_{\mathrm{j} \text { intra-urban or rural }}=\frac{\mathrm{P}_{\mathrm{ju}}}{\mathrm{P}_{\mathrm{j}}} \mathrm{T}_{\mathrm{ju}}+\frac{\mathrm{P}_{\mathrm{jr}}}{\mathrm{P}_{\mathrm{j}}} \mathrm{T}_{\mathrm{jr}} \\
\mathrm{T}_{\mathrm{ju}}=\sum_{\mathrm{i}=1}^{287} \frac{\mathrm{P}_{\mathrm{jui}}}{\mathrm{P}_{\mathrm{ju}}} \lg \left(\frac{\mathrm{P}_{\mathrm{jui}} / \mathrm{R}_{\mathrm{jui}}}{\mathrm{P}_{\mathrm{ju}} / \mathrm{R}_{\mathrm{ju}}}\right) \\
\mathrm{T}_{\mathrm{jr}}=\sum_{\mathrm{i}=1}^{287} \frac{\mathrm{P}_{\mathrm{jri}}}{\mathrm{P}_{\mathrm{jr}}} \lg \left(\frac{\mathrm{P}_{\mathrm{jri}} / \mathrm{R}_{\mathrm{jri}}}{\mathrm{P}_{\mathrm{jr}} / \mathrm{R}_{\mathrm{jr}}}\right) \\
=\frac{\mathrm{P}_{\mathrm{ju}}}{\mathrm{P}_{\mathrm{j}}} \sum_{\mathrm{i}=1}^{287} \frac{\mathrm{P}_{\mathrm{jui}}}{\mathrm{P}_{\mathrm{ju}}} \lg \left(\frac{\mathrm{P}_{\mathrm{jui}} / \mathrm{R}_{\mathrm{jui}}}{\mathrm{P}_{\mathrm{ju}} / \mathrm{R}_{\mathrm{ju}}}\right)+\frac{\mathrm{P}_{\mathrm{jr}}}{\mathrm{P}_{\mathrm{j}}} \sum_{\mathrm{i}=1}^{287} \frac{\mathrm{P}_{\mathrm{jri}}}{\mathrm{P}_{\mathrm{jr}}}\left(\frac{\mathrm{P}_{\mathrm{jri}} / \mathrm{R}_{\mathrm{jri}}}{\mathrm{P}_{\mathrm{jr}} / \mathrm{R}_{\mathrm{jr}}}\right)
\end{gathered}
$$

Of which, $\mathrm{P}_{\text {jui }}$ indicates the basic public service level of urban areas $i$ in region $j$, $\mathrm{P}_{\mathrm{ju}}$ indicates the basic public service level of urban areas in region $j ; \mathrm{P}_{\mathrm{jri}}$ indicates the basic public service level of the rural area $i$ in region $j, \mathrm{P}_{\mathrm{jr}}$ indicates the basic public service level of rural areas in region $j ; \mathrm{R}_{\text {jui }}$ indicates the population of the urban area $i$ in region $j, \mathrm{R}_{\mathrm{ju}}$ indicates the total population of urban areas in region $j ; \mathrm{R}_{\mathrm{jr}}$ indicates the population of the rural area $i$ in region $j, \mathrm{R}_{\mathrm{jr}}$ indicates the total population of the rural area in region $j ; \mathrm{R}_{\mathrm{j}}$ indicates the total population of region $j$.

$$
\begin{aligned}
\boldsymbol{T}_{\text {total }} & =\boldsymbol{T}_{\text {inter }- \text { regional }}+\boldsymbol{T}_{\text {intra }- \text { regional }} \\
& =\boldsymbol{T}_{\text {inter }- \text { regional }}+\left(\boldsymbol{T}_{\text {intra }}-\text { regional }- \text { urban }- \text { rural }+\boldsymbol{T}_{\text {intra }- \text { regional }- \text { intra }- \text { urban or rural })}\right. \\
& =\sum_{j=1}^{4} \frac{p_{j}}{p} \lg \left(\frac{p_{j} / R_{j}}{p / R}\right)+\sum_{j=1}^{4} \frac{p_{j}}{p}\left[\frac{P_{j u}}{P_{j}} \lg \left(\frac{P_{j u} / R_{j u}}{P_{j} / R_{j}}\right)+\frac{P_{j r}}{P_{j}} \lg \left(\frac{P_{j r} / R_{j r}}{P_{j} / R_{j}}\right)\right] \\
& +\sum_{j=1}^{4} \frac{p_{j}}{p}\left\{\left[\frac{P_{j u}}{P_{j}} \sum_{i=1}^{287} \frac{P_{j u i}}{P_{j u}} \lg \left(\frac{P_{j u i} / R_{j u i}}{P_{j u} / R_{j u}}\right)+\frac{P_{j r}}{P_{j}} \sum_{i=1}^{287} \frac{P_{j r i}}{P_{j r}} \lg \left(\frac{P_{j r i} / R_{j r i}}{P_{j r} / R_{j r}}\right)\right]\right\}
\end{aligned}
$$




\subsubsection{TOPSIS Evaluation of Basic Public Service Level}

The TOPSIS evaluation method is a technique for ordering preferences by similarity to an ideal solution. The basic idea is that, based on the original evaluation matrix, a dimensionless method is used to process the data to obtain a standardised matrix. Once this has been done, based on index weighting, it is possible to establish a weighted decision matrix to identify further both the optimal scheme and the worst scheme in the existing scenario. Then, it is possible to calculate the distances between the subject of evaluation and both the optimal and worst schemes, to obtain the degree of relative closeness between each subject and the optimal scheme, and to use this as the basis for evaluation sequencing. The specific steps are as follows:

Firstly, search the relevant data according to the index system, and establish original matrix $\mathrm{X}$ :

$$
X=\left[\begin{array}{cccc}
x_{11} & x_{12} & \cdots & x_{1 n} \\
x_{21} & x_{22} & \cdots & x_{2 n} \\
\vdots & \vdots & & \vdots \\
x_{m 1} & x_{m 2} & \cdots & x_{m n}
\end{array}\right]_{m \times n}
$$

As the evaluation on basic public services involves a larger amount of varying index data, all with different dimensions, magnitudes and amplitudes of variation, direct totalling and comparison becomes unfeasible. Dimensionless processing is therefore required when handling such data. The specific method is as follows:

$$
X_{i}=\frac{x_{i}-\min _{1 \leq i \leq n}\left(x_{i}\right)}{\max _{1 \leq i \leq n}\left(x_{i}\right)-\min _{1 \leq i \leq n}\left(x_{i}\right)}
$$

Of which: $\mathrm{X}_{i}$ is the standardised value of index $i ; x_{i}$ is the original value of index $i$; $\max \left(x_{i}\right)$ is the maximum sample value of index $i$; and $\min \left(x_{i}\right)$ is the minimum sample value.

Normalisation processing is then carried out to the original matrix to obtain the normalised matrix $Y$ :

$$
Y=\left[\begin{array}{cccc}
y_{11} & y_{12} & \cdots & y_{1 n} \\
y_{21} & y_{22} & \cdots & y_{2 n} \\
\vdots & \vdots & & \vdots \\
y_{m 1} & y_{m 2} & \cdots & y_{m n}
\end{array}\right]_{m \times n}
$$

The positive utility index is given by, 


$$
y_{i j}=x_{i j} / \sum_{i=1}^{m} x_{i j}, i=1,2, \ldots, m j=1,2, \ldots n
$$

And the negative utility index is given by:

$$
y_{i j}=\frac{1}{x_{i j}} / \sum_{i=1}^{m} \frac{1}{x_{i j}}, i=1,2, \ldots, m j=1,2, \ldots n
$$

We then use the entropy weight method to determine the attribute weight,

$$
H_{j}=-\sum_{i=1}^{m} y_{i j} \ln y_{i j}
$$

then calculate the index difference degree,

$$
K_{j}=1-\frac{H_{j}}{\ln m}
$$

And finally the entropy weight,

$$
w_{j}=\frac{K_{j}}{\sum_{j=1}^{n} K_{j}}
$$

We use the following formula to convert the decision matrix $X=\left\{x_{i j}\right\}$ to normalised decision matrix $Z=\left\{z_{i j}\right\}$

$$
z_{i j}=x_{i j} / \sqrt{\sum_{i=1}^{m} x_{i j}^{2}}
$$

Form the weighted normalised matrix $G=\left\{g_{i j}\right\}$

$$
G=\left[\begin{array}{cccc}
g_{11} & g_{12} & \cdots & g_{1 n} \\
g_{21} & g_{22} & \cdots & g_{2 n} \\
\vdots & \vdots & & \vdots \\
g_{m 1} & g_{m 2} & \cdots & g_{m n}
\end{array}\right]_{m \times n}
$$

where $g_{i j}=w_{j} \times z_{i j}, i=1,2, \ldots, m ; j=1,2, \ldots n, w_{j}$ is the weight of index $j$.

Screen out the optimal value and worst value of each evaluation index, and build the optimal solution vector $\mathrm{G}+$ and the worst solution vector $\mathrm{G}-$ : 


$$
\begin{aligned}
& G_{j}^{+}=\max \left(G_{1 j}^{+}, G_{2 j}^{+}, \ldots G_{m j}^{+}\right) \quad \mathrm{j}=1, \ldots \mathrm{n} \\
& G_{j}^{-}=\max \left(G_{1 j}^{-}, G_{2 j}^{-}, \ldots G_{m j}^{-}\right) \quad \mathrm{j}=1, \ldots \mathrm{n}
\end{aligned}
$$

Calculate the distances of each evaluation unit with the optimal solution and worst solution respectively:

$$
\begin{aligned}
& D_{i}^{+}=\sqrt{\sum_{j=1}^{n}\left(g_{i j}-g_{i}^{+}\right)^{2}}, i=1, \ldots m \\
& D_{i}^{-}=\sqrt{\sum_{j=1}^{n}\left(g_{i j}-g_{i}^{-}\right)^{2}}, i=1, \ldots m
\end{aligned}
$$

Of which, $D_{i}^{+}$indicates the distance from the optimal solution; $D_{i}^{-}$indicates the distance from the worst solution.

Calculate the relative closeness degree $C_{i}$ between each evaluation unit with the optimal solution:

$$
C_{i}=\frac{D_{i}^{-}}{D_{i}^{-}+D_{i}^{+}}, \quad i=1,2, \ldots m
$$

A larger $C_{i}$ value which is tending towards 1 indicates a smaller distance between this evaluation unit and the optimal solution, that is to say, it is closer to the optimal vector, and the comprehensive evaluation degree is higher.

\subsection{Results and Analysis}

\subsubsection{Descriptive Statistics}

We drew data from the China Statistical Yearbook, the China City Statistical Yearbook and the statistical yearbooks of various provinces and cities in 2015, then applied the TOPSIS method to measure the levels of basic public services in different regions of China (see Table 8.2).

The table demonstrates that public medical health services in the northeast are relatively good, followed by the eastern region, central region, and western region. The public medical health service indices are $0.4034,0.3614,0.3351$ and 0.3048 respectively. The main reason of this kind of result is that the net outflow of population from northeast China has been ongoing for 20 years. In the past 10 years, the net population outflow has exceeded 1 million. No significant adjustments in medical institutions have been made accordingly, so per capita public medical health service 
Table 8.2 The Development Indices of Basic Public Services in Different Regions of China (2015)

\begin{tabular}{l|l|l|l|l|l|l}
\hline & $\begin{array}{l}\text { Eastern } \\
\text { region }\end{array}$ & $\begin{array}{l}\text { Central } \\
\text { region }\end{array}$ & $\begin{array}{l}\text { Western } \\
\text { region }\end{array}$ & $\begin{array}{l}\text { North-eastern } \\
\text { region }\end{array}$ & $\begin{array}{l}\text { Mean } \\
\text { value }\end{array}$ & $\begin{array}{l}\text { Standard } \\
\text { deviation }\end{array}$ \\
\hline Medical health & 0.3614 & 0.3351 & 0.3048 & 0.4034 & 0.3512 & 0.0362 \\
\hline $\begin{array}{l}\text { Compulsory } \\
\text { education }\end{array}$ & 0.3202 & 0.3300 & 0.3260 & 0.2628 & 0.3097 & 0.0273 \\
\hline $\begin{array}{l}\text { Cultural } \\
\text { services }\end{array}$ & 0.3020 & 0.2083 & 0.1741 & 0.2163 & 0.2252 & 0.0471 \\
\hline Social security & 0.5220 & 0.1472 & 0.1127 & 0.2395 & 0.2554 & 0.1608 \\
\hline $\begin{array}{l}\text { Combined } \\
\text { indices }\end{array}$ & 0.3764 & 0.2551 & 0.2294 & 0.2805 & 0.2854 & 0.0556 \\
\hline
\end{tabular}

Source The China Statistical Yearbook, the China City Statistical Yearbook and the statistical yearbooks of various provinces and cities in 2015

resources are relatively abundant. In contrast, since the 1980s, the eastern region has been the main destination of population migration, and the growth in health services cannot keep up with population growth, so public medical health service resources are relatively tight.

The Chinese government has made great efforts to promote compulsory education since 1948. More than $98 \%$ of the country's children now receive compulsory education. Therefore, the level of access to compulsory education is fairly stable across the various regions. Nevertheless, a serious 'brain drain' from Northeast China has created a relative scarcity in high-quality full-time teachers in primary and secondary schools and the compulsory education index is comparatively lower.

The eastern region has the best provision for services promoting social and cultural development, while the north-eastern, central and western regions lag behind in comparison.

The level of development for social security services is far ahead in the eastern region, with a social security index of 0.5220 , followed by the northeast region, with a social security index of 0.2395 . The western and central regions are lag seriously behind in these indices.

Overall, access to compulsory education is the most equally distributed basic public service, with social security the most unequal in terms of access.

Table 8.3 used the TOPSIS method to measure the urban and rural basic public services in different regions of China. It is clear that in terms of compulsory education, medical health, cultural services and social security, urban levels of public services in all major regions exceed that in rural areas. We will analyse this further below. 
Table 8.3 The Development Index of Urban and Rural Basic Public Services in Different Regions of China (2015)

\begin{tabular}{l|l|l|l|l|l|l|l}
\hline \multicolumn{2}{c|}{} & $\begin{array}{l}\text { Eastern } \\
\text { region }\end{array}$ & $\begin{array}{l}\text { Central } \\
\text { region }\end{array}$ & $\begin{array}{l}\text { Western } \\
\text { region }\end{array}$ & $\begin{array}{l}\text { North-eastern } \\
\text { region }\end{array}$ & $\begin{array}{l}\text { Mean } \\
\text { value }\end{array}$ & $\begin{array}{l}\text { Standard } \\
\text { deviation }\end{array}$ \\
\hline $\begin{array}{l}\text { Medical } \\
\text { health }\end{array}$ & $\begin{array}{l}\text { Urban } \\
\text { area }\end{array}$ & 0.3784 & 0.3782 & 0.3088 & 0.4083 & 0.3684 & 0.0327 \\
\cline { 2 - 8 } & $\begin{array}{l}\text { Rural } \\
\text { area }\end{array}$ & 0.2969 & 0.2901 & 0.3029 & 0.4055 & 0.3238 & 0.0424 \\
\hline $\begin{array}{l}\text { Compulsory } \\
\text { education }\end{array}$ & $\begin{array}{l}\text { Urban } \\
\text { area }\end{array}$ & 0.3631 & 0.3559 & 0.3357 & 0.2597 & 0.3286 & 0.0367 \\
\cline { 2 - 8 } & $\begin{array}{l}\text { Rural } \\
\text { area }\end{array}$ & 0.2234 & 0.2994 & 0.3218 & 0.2599 & 0.2761 & 0.0337 \\
\hline $\begin{array}{l}\text { Cultural } \\
\text { services }\end{array}$ & $\begin{array}{l}\text { Urban } \\
\text { area }\end{array}$ & 0.3409 & 0.3082 & 0.2347 & 0.2986 & 0.2956 & 0.0344 \\
\cline { 2 - 8 } & $\begin{array}{l}\text { Rural } \\
\text { area }\end{array}$ & 0.2478 & 0.0998 & 0.1148 & 0.0904 & 0.1382 & 0.0571 \\
\hline $\begin{array}{l}\text { Social } \\
\text { security }\end{array}$ & $\begin{array}{l}\text { Urban } \\
\text { area }\end{array}$ & 0.5705 & 0.1844 & 0.1205 & 0.2743 & 0.2874 & 0.1541 \\
\cline { 2 - 8 } & $\begin{array}{l}\text { Rural } \\
\text { area }\end{array}$ & 0.4462 & 0.1062 & 0.1040 & 0.1835 & 0.2100 & 0.1253 \\
\hline $\begin{array}{l}\text { Indices } \\
\text { area }\end{array}$ & $\begin{array}{l}\text { Urban } \\
\text { area }\end{array}$ & 0.4132 & 0.3067 & 0.2499 & 0.3102 & 0.3200 & 0.0527 \\
\cline { 2 - 8 } & Rural & 0.3036 & 0.1989 & 0.2109 & 0.2348 & 0.2370 & 0.0363 \\
\hline
\end{tabular}

Source The China Statistical Yearbook, the China City Statistical Yearbook and the statistical yearbooks of various provinces and cities in 2015

\subsubsection{Inequality of Access to Basic Public Services Among Different Regions}

Using data from the China Statistical Yearbook, the China City Statistical Yearbook and the statistical yearbooks of various provinces and cities in 2015, we applied the Theil index model to measure inequality of access to basic public services at different levels throughout the country.

The results showed that the Theil index of national basic public service is 0.156 $(>0.1)$, indicating that the supply of basic public service at the national level is generally unbalanced. The intra-regional gap of basic public service is higher than the inter-regional gap of basic public service (see Table 8.4).

We mainly observed and compared the availability of basic public services in eastern, central, western and north-eastern regions of China and the gaps between the regions. The results measured by the TOPSIS method showed that the comprehensive indices of basic public service levels were: 0.3764 for the eastern region (highest); followed by 0.2805 for northeast region; 0.2551 for central region; and 0.2294 for the western region (lowest). The basic public service level of the eastern region is far 
Table 8.4 Contributions of inter-regional and intra-regional to Theil index (2015)

\begin{tabular}{l|l|l|l|l|l}
\hline & $\begin{array}{l}\text { Medical } \\
\text { health (\%) }\end{array}$ & $\begin{array}{l}\text { Compulsory } \\
\text { education (\%) }\end{array}$ & $\begin{array}{l}\text { Cultural } \\
\text { facilities (\%) }\end{array}$ & $\begin{array}{l}\text { Social } \\
\text { security (\%) }\end{array}$ & $\begin{array}{l}\text { Combined } \\
\text { index (\%) }\end{array}$ \\
\hline Inter-regional & 10 & 13 & 10 & 16 & 12 \\
\hline Intra-regional & 90 & 87 & 90 & 84 & 88 \\
\hline
\end{tabular}

Source The China Statistical Yearbook, the China City Statistical Yearbook and the statistical yearbooks of various provinces and cities in 2015

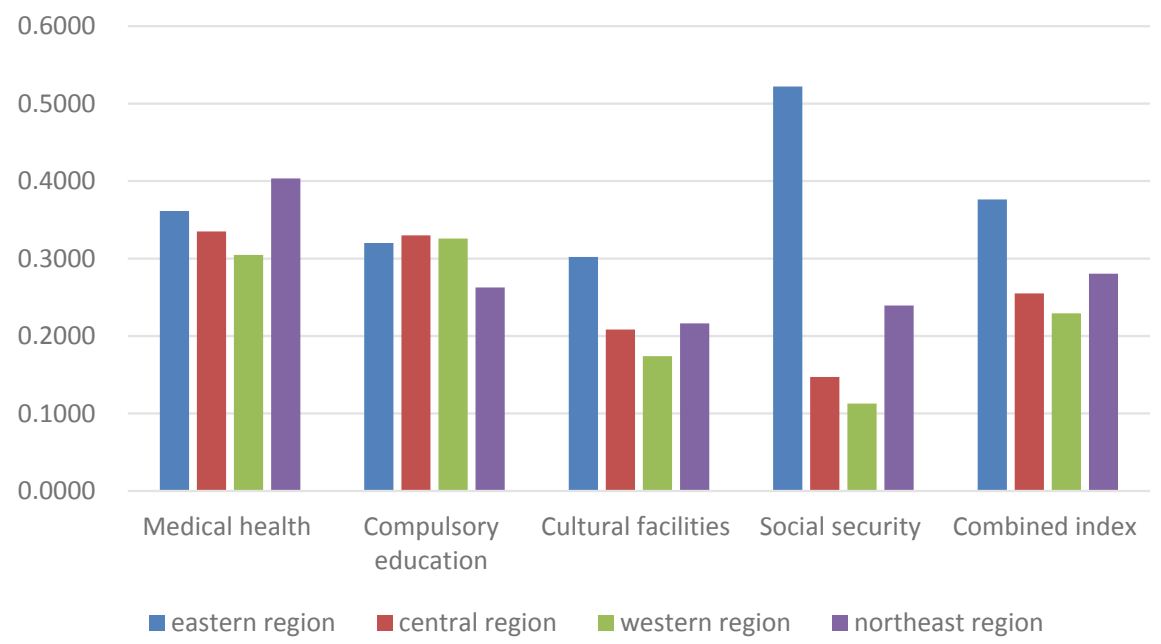

Fig. 8.1 Comparison of levels of basic public services in four regions of China (2015). Source TOPSIS scores computed using data from the China Statistical Yearbook, the China City Statistical Yearbook and the statistical yearbooks of various provinces and cities in 2015

ahead of other regions, and western region lags behind other regions (see Figs. 8.1 and 8.2).

We found that compulsory education had the highest degree of equality across the different regions, followed by medical health , and public cultural services. Social security had the greatest inequality of access (see Figs. 8.2 and 8.3).

\subsubsection{Urban-Rural Inequality of Access to Basic Public Services}

We mainly observed and analysed the supply balance and availability of basic public services in a region. The evaluation results showed that from an intra-regional perspective, the most unequally distributed aspects of basic public services were 


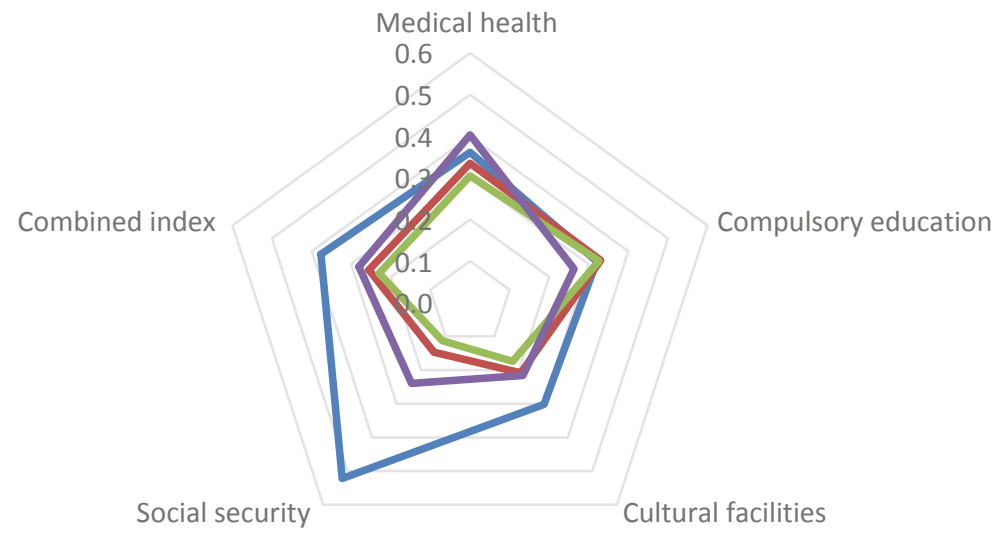

-eastern region $\longrightarrow$ central region $\quad$ western region $\quad$ northeast region

Fig. 8.2 Comparison of basic public service gap in four regions of China (2015). Source TOPSIS scores computed using data from the China Statistical Yearbook, the China City Statistical Yearbook and the statistical yearbooks of various provinces and cities in 2015

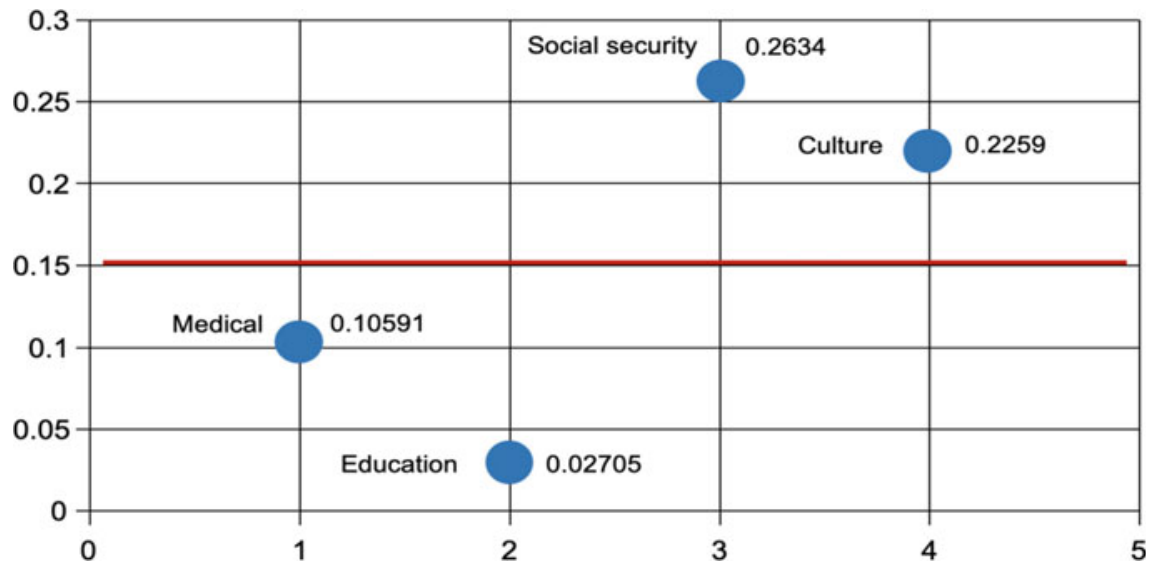

Fig. 8.3 Comparison of inequality in access to various basic public services in four regions of China (2015). Source calculated according to the relevant statistical data in the China Statistical Yearbook, the China City Statistical Yearbook and the statistical yearbooks of various provinces and cities in 2015

mainly concentrated around urban-rural divisions and focused primarily on cultural services provision and social security (see Table 8.5 ).

Based on the per capita resource, we observed the urban/rural discrepancies in the supply of various provincial basic public services. The results showed that although various per capita resources in urban areas were generally higher than those in rural 
Table 8.5 Contributions of regional groups of China to Theil index (2015)

\begin{tabular}{l|l|l|l|l|l}
\hline & $\begin{array}{l}\text { Medical health } \\
(\%)\end{array}$ & $\begin{array}{l}\text { Compulsory } \\
\text { education }(\%)\end{array}$ & $\begin{array}{l}\text { Cultural } \\
\text { facilities }(\%)\end{array}$ & $\begin{array}{l}\text { Social security } \\
(\%)\end{array}$ & $\begin{array}{l}\text { Combined } \\
\text { index }(\%)\end{array}$ \\
\hline Urban-rural & 30 & 12 & 35 & 50 & 41 \\
\hline Inter-urban & 20 & 22 & 39 & 26 & 30 \\
\hline Inter-rural & 50 & 66 & 26 & 24 & 29 \\
\hline
\end{tabular}

Source Theil index applied to the relevant statistical data in the China Statistical Yearbook, the China City Statistical Yearbook and the statistical yearbooks of various provinces and cities in 2015

regions, there were differences across individual provinces . In some rural areas in certain provinces , the per capita compulsory education resource and public medical health service resources exceeded those available in urban areas. This indicated that during the urbanisation process, as the rural population moved towards cities and towns or travelled to work outside their communities, the rural population decreased sharply. In some areas, public service resources allocated to the permanent or 'registered' population were seriously wasted or used inefficiently (see Figs. 8.4, 8.5, 8.6 and 8.7).

For example, in the past 20 years, the number of primary school students in China's urban areas has increased by more than 28 million, but the number of schools has decreased by 45,000 . Conversely, with the rapid advancement of urbanisation, the number of students in rural areas has continued to decline sharply. In recent years, however, the number of newly built schools in rural areas has increased year by year. This reminds us that we should not adopt rigid and mechanical methods to promote the equalisation of basic public services. Instead, we must reasonably optimise public service resources based on population distribution.

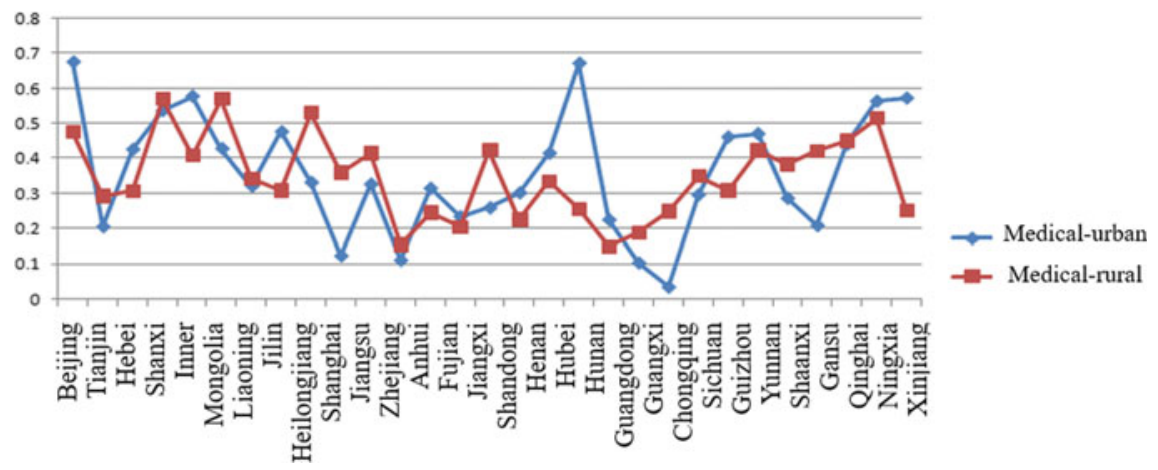

Fig. 8.4 Urban-rural comparison of basic medical public service supply levels across major provinces on the Chinese mainland (Calculated according to resources owned per 10,000 persons). Source The China Statistical Yearbook, the China City Statistical Yearbook and the statistical yearbooks of various provinces and cities in 2015 (Because the statistics of Xizang Province and Hainan Province are incomplete, they are temporarily not included in this evaluation) 


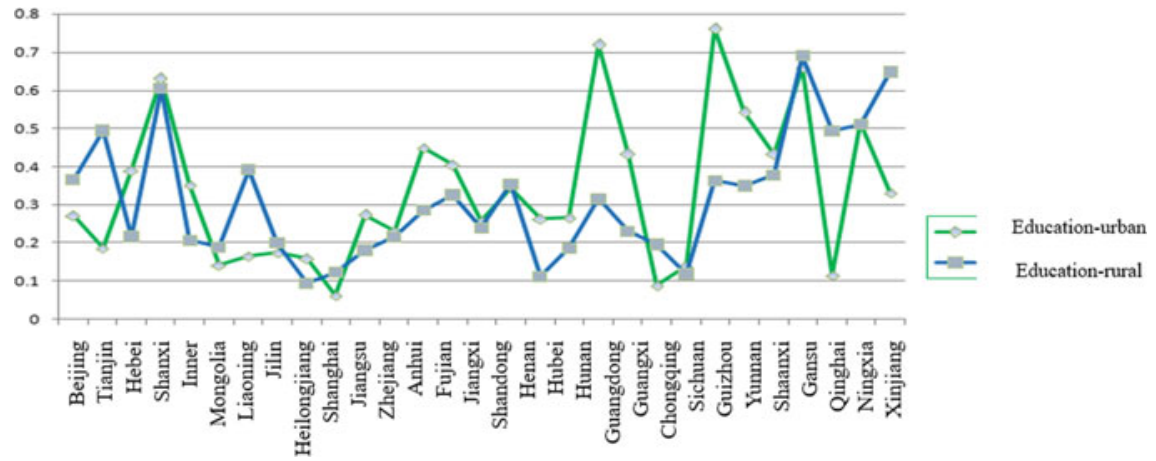

Fig. 8.5 Urban-rural comparison of basic educational public service supply levels across major provinces in mainland China (Calculated according to resources owned per 10,000 persons). Source The China Statistical Yearbook, the China City Statistical Yearbook and the statistical yearbooks of various provinces and cities in 2015 (Because the statistics of Xizang Province and Hainan Province are incomplete, they are temporarily not included in this evaluation)

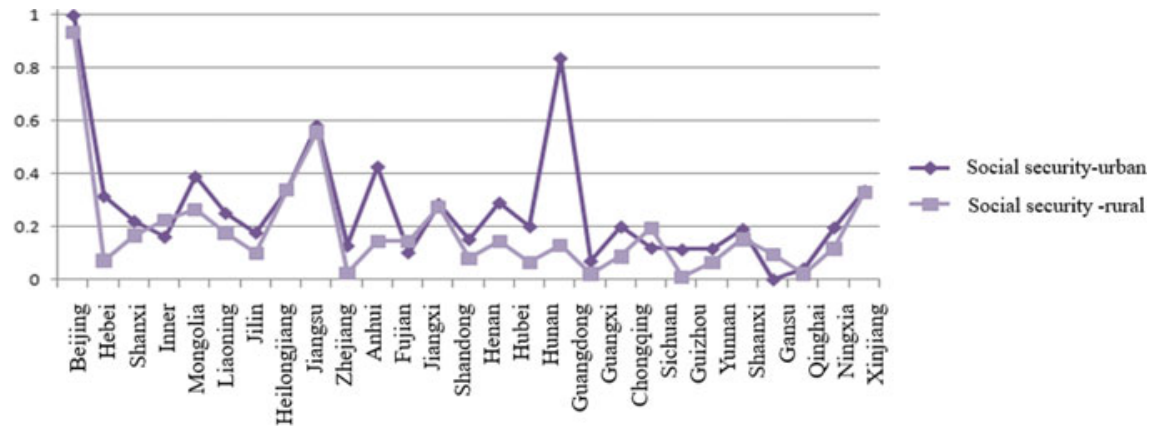

Fig. 8.6 Urban-rural comparison of social security levels across major provinces in mainland China. Source The China Statistical Yearbook, the China City Statistical Yearbook and the statistical yearbooks of various provinces and cities in 2015 (Because the statistics of Xizang Province and Hainan Province are incomplete, they are temporarily not included in this evaluation)

Figure 8.8 below shows the urban/rural gaps within the provision of basic public services among various provinces throughout the country. We find that generally, the gaps are larger in regions with a more developed economy. The urban/rural discrepancy was smaller in some regions, but their basic public service levels were also relatively lower, thus presenting a low-level balance (see Fig. 8.8). 


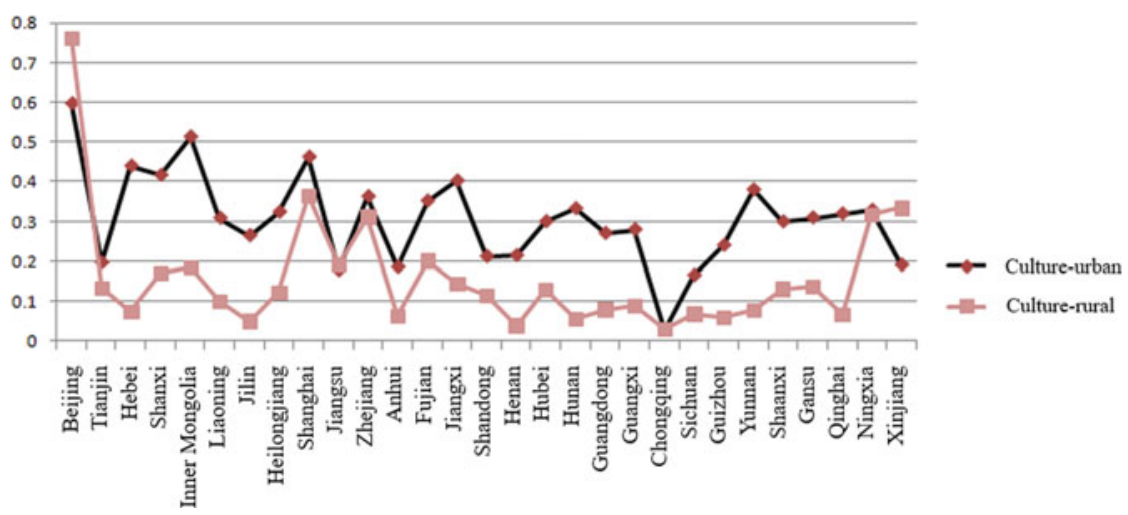

Fig. 8.7 Urban-rural comparison of public cultural service supply levels across major provinces in mainland China (calculated according to resources owned per 10,000 persons). Source The China Statistical Yearbook, the China City Statistical Yearbook and the statistical yearbooks of various provinces and cities in 2015 (Because the statistics of Xizang Province and Hainan Province are incomplete, they are temporarily not included in this evaluation)

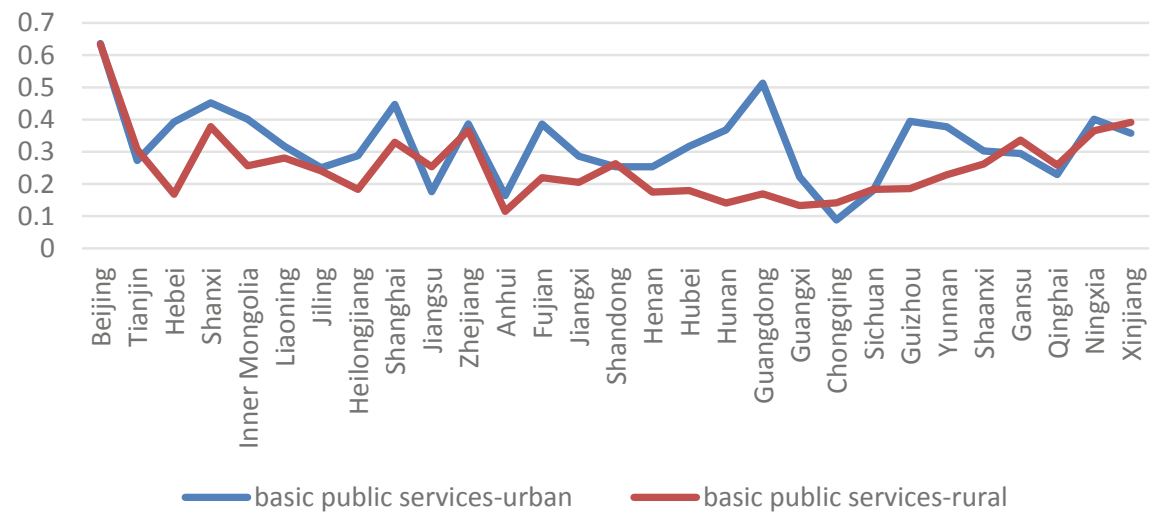

Fig. 8.8 Urban-rural comparison of basic public services in major provinces of the Chinese mainland. Source calculated according to the relevant statistical data in the China Statistical Yearbook, the China City Statistical Yearbook and the statistical yearbooks of various provinces and cities in 2015. (Because the statistics of Xizang Province and Hainan Province are incomplete, they are temporarily not included in this evaluation)

\subsubsection{Intra-Urban Inequality in Access to Basic Public Services}

In this section, we analyse the gaps in access to basic public services between migrant workers and the local urban population from the perspectives of employment, education, public housing and social security. 
The public employment service system provided by regional governments for migrant workers has improved gradually over recent years, but up to 2017, still only about a third of migrant workers had received appropriate vocational skills training.

According to the Research Report on the Situations of Left-Behind Children in Rural Areas and Urban-Rural Migrant Children of China published by the All-China Women's Federation in 2013, there are 35,810,000 urban-rural migrant children across the country. These children accompany their parents as they migrate to cities. Pre-school migrant children (0-5) make up some $27.4 \%$ of the total. School-age children in the compulsory education stage (primary school and junior middle school stages, 6-14) comprise $41.1 \%$, and older migrant children (15-17) another $31.5 \%$. Most migrant children within the age range for compulsory education (aged 6-14) can study in local primary schools or junior high schools. However, it is harder for pre-school aged migrant children to enter kindergartens and for older ones to enter high schools. In recent years, as the Chinese government pays more attention to the education of migrant children, urban public and private schools are openingup to these children, and the education for migrant children of migrant workers has greatly improved. According to the Migrant Workers Monitoring Survey Report 2018 published recently by the National Bureau of Statistics, the schooling rate of migrant children of migrant workers in the compulsory education stage has reached 98.9\%. The kindergarten admittance rate of migrant children aged 3-5 (including pre-school) has reached $83.5 \%$, and the degree of satisfaction of migrant workers with their children's education has reached $75.3 \%$. Nevertheless, those children outside the age for compulsory education who want to leave for local cities to continue their education at senior high school or university still face some institutional barriers.

When it comes to access to cultural and sports services, our research in 2010 and 2014 found that most migrant workers rarely or never used the available public cultural service facilities or participated in related activities. However, more recent research shows that more than a quarter $(26.5 \%)$ of migrant workers now participate in activities organised by local communities. More than $10 \%$ of migrant workers now participate in cultural recreation, sports, training and learning activities in their spare time. ${ }^{3}$ For example, Hangzhou has carried out a series of public cultural services for its migrant population, providing a lecture hall for citizens, migrant workers cinema, supermarket, and migrant workers culture club. These play a very positive role in improving the cultural life of migrant workers and strengthening their social cohesion.

The main types of accommodation available for Chinese migrant workers in 2009 were the employer's dormitory (33.9\%), factory premises or production and operation sites (17.9\%) and rented houses (34.6\%). By 2018, the proportions had changed with the employer's dormitory accounting for $12.9 \%$, rented houses for $61.3 \%$ and private self-bought property at $19 \%$, a rise from $0.8 \%$ in 2009 . The per capita living

\footnotetext{
${ }^{3}$ Data source: National Bureau of Statistics, Migrant Workers Monitoring Survey Report 2017, and Migrant Workers Monitoring Survey Report 2018.
} 


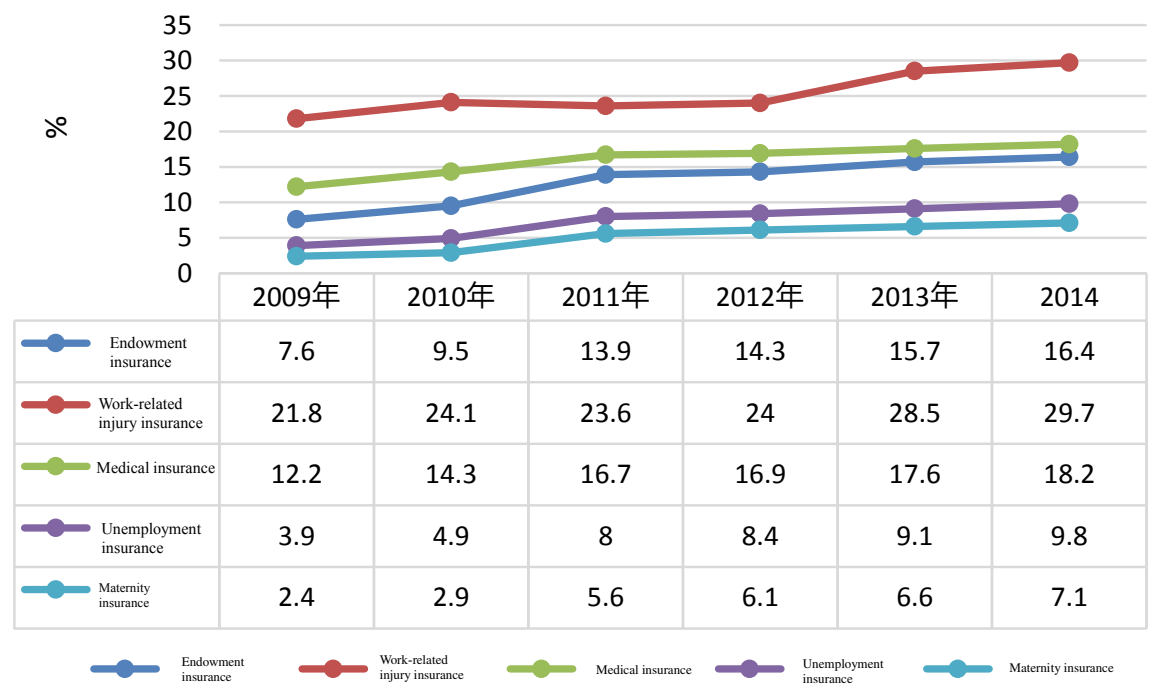

Fig. 8.9 Percentages of migrant workers participating in social security. services from 2009 to 2014. Source arranged according to the relevant data in the Migrant Workers Monitoring Survey Report 2009 to 2014, National Bureau of Statistics

space reached $20.2 \mathrm{~m}^{2}$. Some $2.9 \%$ of migrant workers are entitled to governmentsubsidised housing, including $1.3 \%$ of public rental housing and $1.6 \%$ of self-bought government-subsidised housing. ${ }^{4}$

From 2009 to 2014, the proportions of Chinese migrant workers participating in various insurance schemes increased, including employment injury insurance (from $21.8 \%$ to $29.7 \%$ ), medical insurance (from $12.2 \%$ to $18.2 \%$ ), endowment insurance (from $7.6 \%$ to $16.4 \%$ ), unemployment insurance (from $3.9 \%$ to $9.8 \%$ ) and maternity insurance (from $2.4 \%$ to $7.1 \%$ ) (see Fig. 8.9). Although in recent years, the coverage rate of social security services for migrant workers increased markedly, a larger gap still exists compared with the urban population. During the year 2014, for example, where the social security data is relatively complete, the proportions of migrant workers participating in employment injury insurance, medical insurance, endowment insurance, unemployment insurance and maternity insurance are only equivalent to $1 / 2,1 / 4,1 / 4,1 / 4$ and $1 / 6$ of the coverage rates of urban employees (see Fig. 8.10).

\footnotetext{
${ }^{4}$ Data source: National Bureau of Statistics, Migrant Workers Monitoring Survey Report 2009, and Migrant Workers Monitoring Survey Report 2018.
} 


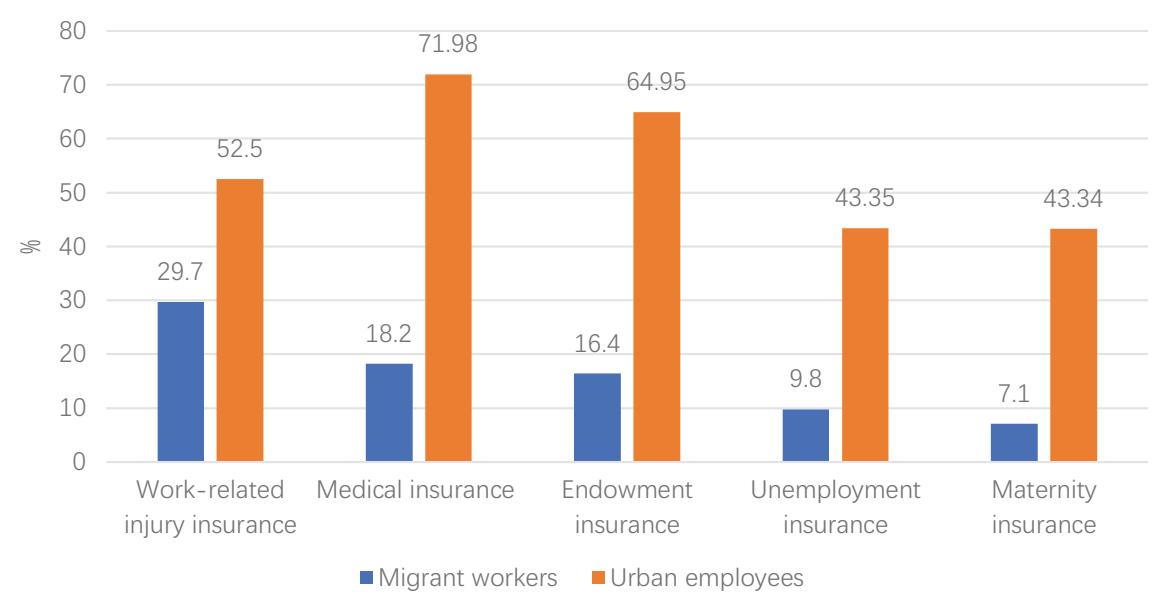

Fig. 8.10 Comparison of social security coverage between migrant workers and urban employees in 2014. Source calculated according to the relevant statistical data in the China City Statistical Yearbook 2015 and the Migrant Workers Monitoring Survey Report 2014

\subsection{Policy Implications}

In the light of these very significant inequalities in access to basic public services between migrant workers and the local urban population across different regions of China, what should policy makers do? In this section, we summarise some policy implications.

\subsubsection{Administrative and Expenditure Responsibilities}

In a market economy, the government's most important administrative function is the provision of basic public services. The clear definition of administrative and expenditure responsibilities at all levels of government and the establishment of systems that combine fiscal and regulatory powers is both the precondition and basis for promoting equitable coverage for regional public services.

The clear definition and demarcation between administrative and financial responsibilities between central and local governments would encourage collaboration and help ensure that different levels of government carry out their duties and maximisation efficiency. 


\subsubsection{Transfer Payment System}

Most countries implement a single vertical transfer payment system for the disbursement of public funds from central government. The typical transfer flow runs from central to local government and down to the 'lowest' levels through a hierarchical system. In China, there is a large development gap between the eastern and the central and western regions, and the central government's financial resources are relatively limited. There is a need to establish a rational and consistent financial transfer payment system so as to promote regional equalisation of basic public services.

Horizontal transfer payments typically operate across the same tiers of government. A local government with a relatively developed economy will directly transfer a portion of its fiscal revenue to the less developed regions to support their development. The most developed regions within eastern China are currently approaching the levels of developed countries worldwide. These regions have the capacity and conditions to support less developed areas financially. A horizontal transfer payment system will promote co-ordinated inter-regional development and enhances overall economic development at a national level.

In the meantime, we need to facilitate vertical transfer payments below the provincial level. We should strengthen transfer payments between provincial and county levels, to equip and empower the lower tiers of local government to own and manage expenditure effectively to meet regional requirements. The second point is to actively promote financial system reform at county and town-level to best achieve the financial system reforms necessary to achieve consistency and deliver more equal access to public services.

\subsubsection{Public Service Supply}

In order to satisfy the increasingly rising public demand for more and higher quality services, we must align relations appropriately between government, market and society, integrate public service resources, and update service delivery. A coordinated approach gives full play to the positive roles of market and society and ensures that government takes the lead in providing public services.

A marketisation process is necessary to achieve and maintain service efficiency and equality. The procurement of specific services can be devolved from government to appropriate and suitably qualified social organisations or profit-making companies. The government then purchases these services according to quantity and quality.

Another step would be to change the payment model by adopting a voucher system. For education, medical health, provision for the aged, employment training and other services that relate directly to individuals, the government's prime responsibility is to intervene when demand cannot be satisfied, or else the price exceeds public purchasing power. At this point, government can provide appropriate subsidies to guarantee that all residents can benefit from these services. 
A third objective would be to establish new investment systems to help secure the participation of social organisations. Appropriate and qualified social or profitmaking organisations can be allowed to expand the investment channels available for public services through franchising, competitive tender, rental contracts, or government participation. If we take social security as an example, we can build a cooperative platform between commercial insurance and social insurance, to harness the advantages of commercial insurance provision. We also need to resolve current problems in community management and give more support to people with particular needs. By combining the advantages of assistance, welfare and insurance, we can establish a comprehensive and water-tight system with the participation of government, society, employers and employees.

Public services can be planned and delivered more accurately and intelligently with input from social organisations. As they are rooted in specific communities, they offer the great advantage of grass-roots insights to help tailor services to meet local conditions. Services can then be delivered in a more timely, appropriate and professional way to satisfy local demand.

\subsubsection{Integration of Resources}

The current low level of coverage and access to public services for migrant workers is a major challenge and concern. There is a need to increase access and continue to deepen the reform of the household registration system. We must enable qualified migrant workers to settle in cities with as much right and opportunity to access quality public services as the permanent and registered resident population.

Disparities between urban and rural services lie largely in service inefficiencies and poor service quality in the countryside. We should improve levels of take-up and service efficiency and quality to redress this imbalance. This can primarily be achieved by combining and rationalising systems and service delivery. For instance, basic urban medical insurance and new rural cooperative medical care systems can be combined into a provincially unified and integrated whole. The same could apply to social security endowments and subsistence allowance systems resulting in a relatively unified system but pitched at a level appropriate for local conditions. A balanced approach to the allocation of resources and service delivery could maximise social security coverage and reduce the gaps in service level between urban and rural areas.

The western region especially faces double challenges of lower service quality and insufficient coverage. In the future, we should look to increase both coverage and quality across less developed regions. Improved payment transfer systems at all levels of government should help to achieve this. At the same time, investment, training and policies should strengthen targeted support to improve the professionalism of public service development, especially in poorer and less developed regions. 


\subsubsection{Use of Information Technology}

The construction of appropriate information platforms and the deployment of digital information technology is crucial if we are to improve the quality and efficiency of public service delivery across China. The marketisation, planning and socialisation of service supply depends on the development of national and provincial data platforms to serve various priority services.

A cohesive and unified social security information system is vital. This could take the form of a 'One Card' approach with applications across social and medical insurance, unemployment and maternity benefits. Information could be shared across employment and labour relations services and social assistance institutions.

Another example would be compulsory education, where online technologies could allow resource-sharing to gradually reduce regional and urban/rural differences and disparities between different types of school. Within medical health, we should actively promote online inquiry, telemedicine, and resource-sharing across regions and between towns and the countryside.

Information technology should also be utilised to build user-friendly, barrier-free transfer and renewal systems for social insurance services. Levels of expenditure could be equalised between educational provision in urban and rural areas to follow the principle of 'expenditure moving with people'- the allocation of resources to the points of greatest need.

\subsubsection{Standardisation of Laws and Regulations}

The gradual establishment and improvement of laws and regulations around basic public services is of great significance in achieving equality of access to public services. The process involves the following three aspects:

First, experience from other countries shows that it is necessary to establish a basic framework for the division and allocation of inter-governmental administrative and financial powers and responsibilities. In doing so, we ought to clearly and specifically stipulate financial authority, rights and obligations at all levels of governments. At present, China has no legal provision for the division of inter-governmental administrative and fiscal power. Inter-governmental relations currently generally follow the principal guidance of Communist Party and government documents. This creates a degree of policy instability at a local level as it becomes easy to distort investment, consumption and labour market behaviour. Moreover, some local government agencies may limit the free flow of labour and other production factors to gain regional advantage, an example of what is known in the economics literature as the 'externality' problem. Such 'externalities' arise when the behaviour of a person, firm or government department 'changes the cost of some subsidy or alters the revenues collected from some tax, thereby affecting the wellbeing of taxpayers in general' (Browning 1999, p.3). The financial externality problem arises when one 
local government's financial investment benefits or damages others but is unable to charge or compensate them. The administrative and financial externality problem may influence the normal exercise of administrative and financial powers of local governments. Most importantly, the fiscal externality problem makes it harder to divide central and local responsibility. The central government may shift their administrative responsibilities away and on to the local agencies. To avoid situations of this kind we must strengthen the legal system to establish clear lines of authority for inter-governmental administrative and financial powers.

The second aspect is the need to further develop more detailed legislation relating to public services. There is a need within China for greater legislative definition within public service areas like compulsory public education and health care, for instance. Public education is governed by policies contained in Education Law and Compulsory Education Law. Within public health care there is the Law on the Prevention and Control of Infectious Diseases and the Health Law. These policies tend to govern broad brush policy areas and often provide insufficient detail for those charged with implementing the policies to follow. In some instances, those delivering services have no option but to act 'at will' without clear or adequate guidelines, introducing uncertainty, inconsistency and even serious compromises in the quality or appropriateness of service delivery.

Third, further development is needed on the regulation of the marketisation and socialisation of public services. China is consistently applying measures to marketise and socialise service delivery but with few specialised laws and regulations to govern and supervise the processes involved. We must accelerate the formulation and introduction of relevant legislation to build a more open, equal and fair environment for the marketisation and socialisation of basic public services.

\subsection{Conclusions and Recommendations}

In this chapter we have provided a systematic way of quantifying inequalities in access to public services arising from the dual-household registration system. We reported four main sets of results. Firstly, there are still marked inequalities in access to basic public services between urban populations and migrant workers. These migrant workers generally face more difficulties in receiving medical treatment, entering schools, obtaining social security provision, and enjoying entertainment. Services for migrant workers in urban areas are poorly available and narrow in scope and these are the main reasons for the sense of a lack of belonging and integration among these groups in Chinese cities.

Secondly, there is an urgent need for improving service quality in education and medical health provision in rural areas. It is not a problem of insufficient supply as rural areas have received compulsory education and medical health provision for many years. The issue is one of quality and a disparity between rural and urban areas. At present, the largest gap occurs within public cultural services, often seriously insufficient in rural areas. In recent years, although China has made great efforts to 
establish public cultural services in rural areas, the 'take-up' is generally low due to a failure to grasp the real requirements of people in the countryside. The Rural Library Project can serve as one example. In many rural areas the population largely consists of children and elderly people left behind as migrants headed to the cities to find work. The elderly generally have a lower degree of education and seldom read. There are often fewer books for children in rural libraries which largely stock reference books on agricultural science and other practical applications. Consequently, many book resources are underutilised.

Thirdly, the overall levels of access to basic public services vary very little across China's eastern, central and northeast regions. The basic public service level within the western region does lag behind the others in relative terms. The public service which shows the smallest regional variance is basic education. There are greater regional differences in public cultural services and social security, especially in central and western regions, which trail behind the other regions.

Fourthly, when examined from the perspective of the whole country, it is evident that basic public services in China are generally unbalanced in terms of access and coverage. The gaps are more evident between regions rather than within each region itself. These gaps are most clearly seen in the disparity between urban and rural public services and between permanent and migrant populations in cities. Furthermore, China's basic public services are currently characterised by the coexistence of a 'dualised' urban-rural divide and also 'fragmentation' between regions. An example is a difficulty in transferring and renewing social security claims and entitlements, which forms a great barrier for the reasonable flow of migrant workers. Finally, there are disparities between increasing public demand for basic services and improved quality of life and the relatively low level of development, coverage and quality of some of the available services.

It is clear then that China still has a long way to go to promote and realise consistent provision of basic public services. There remain large differences in the economic level and financial strengths of different regions. Gaps in provision cannot be filled in a short time. On the other hand, China is undergoing rapid urbanisation and the pace of this process makes the widening of provision to migrant workers a key and pressing problem. Equally, it is not enough to simply provide wider coverage of basic public services, issues of supply, quality and public satisfaction should also be taken into account. In order to promote urbanisation and the 'citizenisation' of migrant workers, and to establish a financial system with matched financial and administrative power, China needs to:

- delineate administrative and expenditure responsibilities,

- develop a transfer payment system,

- diversify and enhance public service supply,

- integrate resources,

- use information technology to reduce public service inequality,

- standardise laws and regulations. 


\section{References}

Browning EK (1999) The myth of fiscal externalities. Public Finance Rev 27(1):3-18

Cai F, Du Y, Wang M (2005) Political economic analysis of labor mobility. SDX Joint Publishing Company, Shanghai

Feng X, Niu S, Li J (2014) Spatial Evolution and Influence Factors of Chinese Municipal Basic Public Services Equalization. J Lanzhou Univ (Social Science) 3:86-93

Hu A, Wang H, Zhou S (2013) Evaluation on national public service development during "11th Five-Year Plan." Chinese Public Administration 4:20-24

Huang X, Fang Q (2008) Study on regional differences of health expenditure in China. Chinese Health Econ 4:20-23

Ji W (2009) Research on urban integration of migrant workers from the perspective of social capital. Economic Science Press, Beijing

Liu C, Xu J et al (2008) Research on the migrant workers' citizenisation process in China. People's Publishing House, Beijing

Lu H et al (2012) Report on the equalization progress of China's basic public services. People's Publishing House, Beijing

Ouyang Q, Ding R (2011) A study on appropriateness of Chinese regional social security level. China Labor 4:13-16

Ren Q (2009) Changes in the differences of inter-provincial public service levels in China: a measurement method using the gini coefficient. J Central Univ Finance Econ 11:5-9

Wang X (2012) An empirical analysis of inter-regional equalization level of Chinese basic public culture service-investigation based on data comparison between 1999 and 2009. Public Finance Res 3:26-29

Yu Y (2012) Analysis of the gap and impact factors of inter-regional basic public service inputs in China-taking compulsory education as an example. J Yunnan Univ Finance Econ 2:34-75

Zhang G (2008) Citizenisation of Chinese migrant workers: a study from the perspective of social costs. People's Publishing House, Beijing

Zhao L (2006) Research on urbanization issues of urban migrant workers. Population J 4:40-45

Zhao Y (2013) Comprehensive evaluation of rural primary medical service level in different provinces and regions of China—based on factor analysis method. Public Finance Res 4:28-33

Zhao Y, Wang F (2002) Economic Status Acquisition of Urban-Rural Migrant Population and Determinants. Chinese J Popul Sci 4:8-15

Open Access This chapter is licensed under the terms of the Creative Commons Attribution 4.0 International License (http://creativecommons.org/licenses/by/4.0/), which permits use, sharing, adaptation, distribution and reproduction in any medium or format, as long as you give appropriate credit to the original author(s) and the source, provide a link to the Creative Commons license and indicate if changes were made.

The images or other third party material in this chapter are included in the chapter's Creative Commons license, unless indicated otherwise in a credit line to the material. If material is not included in the chapter's Creative Commons license and your intended use is not permitted by statutory regulation or exceeds the permitted use, you will need to obtain permission directly from the copyright holder.

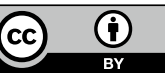

